BMJ Open Sport \& Exercise Medicine

\title{
Anthropometric, physiological characteristics and rugby-specific game skills discriminating Zimbabwean under-16 male adolescent rugby players by level of competition
}

\author{
Matthew Chiwaridzo, ${ }^{\oplus}$ Gillian D Ferguson, ${ }^{2}$ Bouwien C M Smits-Engelsman²
}

\begin{abstract}
To cite: Chiwaridzo M, Ferguson GD,

Smits-Engelsman BCM. Anthropometric, physiological characteristics and rugbyspecific game skills discriminating Zimbabwean under-16 male adolescent rugby players by level of competition. BMJ Open Sport \& Exercise Medicine 2019;5:e000576. doi:10.1136/ bmjsem-2019-000576
\end{abstract}

- Additional material is published online only. To view please visit the journal online (http://dx.doi.org/10.1136/ bmjsem-2019-000576).

Accepted 2 August 2019

Check for updates

\section{(c) Author(s) (or their} employer(s)) 2019. Re-use permitted under CC BY-NC. No commercial re-use. See rights and permissions. Published by BMJ.

${ }^{1}$ Rehabilitation, University of Zimbabwe College of Health Sciences, Harare, Zimbabwe ${ }^{2}$ Health and Rehabilitation Sciences, Faculty of Health Sciences, University of Cape Town, Observatory, South Africa

Correspondence to Matthew Chiwaridzo; matthewchiwaridzo@yahoo. co.uk

\section{ABSTRACT}

Objectives Despite growing popularity of adolescent rugby in Zimbabwean schools, little is known about qualities or skills of schoolboy rugby players and how they differ by competitive level. Therefore, the aim of the current study was to identify anthropometric, physiological characteristics and rugby-specific game skills capable of discriminating under-16 (U16) RU players across three proficiency levels.

Methods Following development of School Clinical Rugby Measure test battery, elite rugby players $(n=41)$, subelite rugby players $(n=30)$ and non-rugby players $(n=29)$ were enrolled and tested for height, sitting height, body mass, skinfolds, speed, agility, upper and lower muscular strength and power, prolonged high-intensity intermittent running ability, tackling, passing and catching in a cross-sectional study.

Results Elite rugby players displayed significantly better scores for all physiological tests and game skills compared with either subelite or non-rugby players, except for Sit-and-Reach, $20 \mathrm{~m}$ speed and L-run tests. However, only vertical jump (VJ) and Yo-Yo Intermittent Recovery Test Level 1 (Yo-Yo IRT L1) significantly improved with increasing competitive level. In addition, elite rugby players showed significantly better scores for tackling $(p<0.001)$ and catching $(p<0.001)$ compared with subelites. No statistical differences were observed across competitive levels for height $(p=0.43)$, sum of seven skinfolds $(p=0.26)$ and passing $(p=0.27)$.

Conclusion Since VJ and Yo-Yo IRT L1 improved with increasing playing standard, these findings possibly highlight physiological attributes important in elite schoolboy rugby in Zimbabwe. Additionally, development and training of tackling and catching skills in U16 schoolboy rugby is important since they are linked to higher playing standard.

\section{INTRODUCTION}

Worldwide, rugby union (RU) is played across a wide age spectrum from junior to senior level. ${ }^{1}$ Notwithstanding its popularity in young 'novices' between 9 and 11 years, ${ }^{2}$ serious competitive RU commences in adolescence

\section{What are the new findings?}

Vertical jump test scores significantly improve with increasing level of competition in under-16 (U16) Zimbabwean schoolboy rugby players.

- The Yo-Yo Intermittent Recovery Level 1 test effectively discriminated Zimbabwean elite U16 rugby players from sub-elite or non-rugby players and concomitantly, discriminated subelite from non-rugby players.

- Better tackling proficiency and catching ability are linked to attainment of elite status in schoolboy rugby among U16 players in Zimbabwe.

especially at the under-16 (U16) age category. ${ }^{3}$ Importantly, this period marks the transitional phase between younger (13-15 years) and older (17-18 years) rugby age categories. Moreover, adolescent RU is physically and technically demanding requiring young players to have fitness components and technical skills commensurate with level of competition. ${ }^{5}$ As such, an assessment of qualities or skills for U16 male adolescents involved in competitive rugby and how these attributes differ by level of competition is important.

Although there are numerous studies documenting the characteristics of male adolescents playing U13 to U19 competitive rugby, ${ }^{6-13}$ no such studies have been conducted for Zimbabwean school-based adolescent male rugby players. Therefore, there is limited understanding of the qualities of Zimbabwean U16 rugby players playing competitive rugby and how they differ by playing standards. This is a significant shortcoming given the increased popularity RU is currently enjoying in Zimbabwean schools. ${ }^{14}$ Population differences between studies limit extrapolation of data from other countries to inform contextual strategies on talent identification and team 
selection. However, the general notion in literature is that male adolescent rugby players should be bigger, faster, fitter and more powerful to reflect the collision nature of the sport. ${ }^{9}$ Against that background, this study was conducted to identify anthropometric variables, physiological characteristics and rugby-specific game skills discriminating elite U16 rugby players from subelite and non-rugby players, and concomitantly, differentiating subelite rugby players from non-rugby players. It was hypothesised that anthropometric, physiological characteristics and rugby-specific game skills would improve with increasing playing standard (elite vs subelite vs non-rugby players). These findings may facilitate rugby coaches' understanding of the general attributes contextually important for U16 school athletes to participate in rugby (subelite rugby players vs non-rugby players) and the specific attributes in need of training for the attainment of elite rugby status at U16 age category (elite rugby players vs subelite rugby players).

\section{METHODS}

\section{Research design and participants}

This study utilised a cross-sectional experimental design and had 41 elite, 30 subelite and 29 non-rugby players. The term 'elite' and 'subelite' referred to adolescents playing competitive rugby in the Super Eight Schools Rugby (SESRL) and Co-educational Schools Rugby League (CESRL), respectively. The SESRL is the premier high school rugby league in the country and CESRL is the second most competitive league. ${ }^{15}$ The non-rugby players represented U16 high school cricket players. The rationale for selecting cricket players was based on having an organised and convenient group of athletes with some degree of physical fitness derived from a sport diametrically opposed to rugby in terms of physical and technical demands. Written informed assents and consents were provided by the participants and parents/guardians, respectively.

\section{Procedures}

All selected players undertook protocol assessments based on the School Clinical Rugby Measure (SCRuM) test battery (online supplementary file 1). Briefly, the test battery included anthropometry (height, sitting height, body mass, seven skinfold site measurements), physiological characteristics (speed, agility, upper and lower muscular strength and power, muscle flexibility, prolonged high-intensity intermittent running ability/ endurance) and rugby-specific game skills (tackling proficiency test, passing ability skills test and running and catching ability skills test). The development of the SCRuM test battery and the rationale for inclusion of the selected tests for the corresponding variables has been described elsewhere. ${ }^{15}$

Before the actual testing, all eligible participants were first familiarised to the test items in SCRuM test battery on two consecutive days. Elite U16 male rugby players were then tested twice to estimate the absolute and relative reliability of each SCRuM test item. Singe measure intraclass correlation coefficients (ICC) for two-way random effects (ICC 2, 1) reporting for absolute agreement and coefficient of variation $(\%)$ values are presented for each test item (online supplementary file 1). Baseline results for these players were then compared with data obtained from U16 subelite rugby players and non-rugby players. All rugby players were tested during training and during the rugby competitive season (June-August 2018) by trained research assistants. Experimental test sessions for the cricketers were conducted during the cricket competitive season (September-October 2018). At any day of testing, injured or ill participants were excluded. Each test would be fully explained, demonstrated and then participants would perform standardised warm-up procedures and three submaximal practice trials.

\section{Statistical analysis}

SPSS statistical software V.25.0 was used for analysis, with statistical significance accepted when $\mathrm{p}<0.05$. Shapiro-Wilk's test assessed normality for all continuous variables. Parametric data are presented as mean \pm SD. Using general linear model, univariate one-way analysis of variance (ANOVA) compared group means for each dependent variable by level of competition. In case of significant effects, the Scheffe's post hoc test determined the location of the mean differences given equal variances. Otherwise, for unequal variances, comparisons were performed using the Games Howell test. Independent sample t-test analysed for differences between elite and subelite rugby players for the rugby-specific game skills. Cohen's d effect sizes (ES) were calculated and interpreted as follows: $<0.2$ (trivial), $0.2-0.6$ (small), $>0.6-1.2$ (moderate) and $>1.2$ (large) ${ }^{16}$

\section{RESULTS}

The table 1 shows group comparisons for demographic and SCRuM test items. Online supplementary file 2 compares raw scores for the elite U16 rugby players in the present study with similar age groups in other previous studies from other countries, showing relatively lower values for the Zimbabwean cohort. Overall, no statistically significant differences were observed for sum of seven skinfolds $(\mathrm{F}=1.38, \mathrm{p}=0.26)$, chronological age $(\mathrm{F}=1.18, \mathrm{p}=0.31)$, playing experience $(\mathrm{F}=1.68, \mathrm{p}=0.19)$ across competitive levels and passing ability skill test $(\mathrm{t}=1.12, \mathrm{p}=0.27)$ between groups. Elite $\mathrm{U} 16$ rugby players performed significantly better $(\mathrm{p}<0.05)$ for all physiological characteristics and rugby-specific game skills than the other groups, except for the Sit-and-Reach test. The non-rugby players had significantly better muscle flexibility compared with the rugby players regardless of competitive level $(\mathrm{F}=9.35, \mathrm{p}<0.001)$. Only vertical jump (VJ) and Yo-Yo Intermittent Recovery Level 1 (Yo-Yo IRT L1) effectively discriminated elite U16 rugby players from both subelite rugby players and non-playing rugby players and further differentiated subelite rugby players from non-rugby players. The $20 \mathrm{~m}$ speed test $(\mathrm{F}=2.59$, $\mathrm{p}=0.08)$ and L-run agility test $(\mathrm{F}=2.28, \mathrm{p}=0.11)$ showed 
Table 1 Group comparisons for demographic, anthropometric, physiological characteristics and game-specific skills for U16 elite, subelite and non-rugby players

\begin{tabular}{|c|c|c|c|c|c|c|c|c|c|}
\hline & \multirow{2}{*}{$\begin{array}{l}\text { Elite* }^{*}(\mathbf{n}=\mathbf{4 1}) \\
\text { Mean } \pm S D\end{array}$} & \multirow{2}{*}{$\begin{array}{l}\begin{array}{l}\text { Subelite } \\
(\mathbf{n}=30)\end{array} \\
\text { Mean } \pm S D\end{array}$} & \multirow{2}{*}{$\begin{array}{l}\begin{array}{l}\text { Non-rugbył } \\
(\mathbf{n}=\mathbf{2 9})\end{array} \\
\text { Mean } \pm S D\end{array}$} & \multicolumn{3}{|c|}{ One way ANOVA } & \multirow[t]{2}{*}{$\begin{array}{l}\text { Effect } \\
\text { size* } \dagger^{*}\end{array}$} & \multirow[t]{2}{*}{ 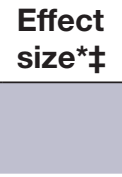 } & \multirow[t]{2}{*}{$\begin{array}{l}\text { Effect } \\
\text { size†‡ }\end{array}$} \\
\hline & & & & $\mathrm{F}$ & $P$ & $\begin{array}{l}\text { Post hoc } \\
\text { analysis }\end{array}$ & & & \\
\hline $\begin{array}{l}\text { Chronological age } \\
\text { (years) }\end{array}$ & $14.9 \pm 0.31$ & $14.8 \pm 0.43$ & $14.9 \pm 0.28$ & 1.18 & 0.31 & & 0.27 & 0.00 & 0.28 \\
\hline $\begin{array}{l}\text { Playing experience } \\
\text { (years) }\end{array}$ & $2.49 \pm 0.51$ & $2.23 \pm 0.68$ & $2.38 \pm 0.56$ & 1.68 & 0.19 & & 0.43 & 0.21 & 0.24 \\
\hline \multicolumn{10}{|l|}{ Anthropometrics } \\
\hline Body mass (kg) & $63.7 \pm 9.09$ & $61.2 \pm 15.5$ & $56.1 \pm 7.83$ & 3.95 & 0.02 & $1>3$ & 0.20 & $0.90 \S$ & 0.42 \\
\hline Height (m) & $1.67 \pm 0.08$ & $1.68 \pm 0.08$ & $1.66 \pm 0.08$ & 0.89 & 0.43 & & 0.13 & 0.13 & 0.25 \\
\hline Biceps (mm) & $5.78 \pm 1.70$ & $6.64 \pm 1.14$ & $7.00 \pm 3.91$ & 2.30 & 0.11 & & 0.59 & 0.40 & 0.13 \\
\hline Triceps (mm) & $9.85 \pm 3.25$ & $9.86 \pm 1.94$ & $10.8 \pm 5.89$ & 0.55 & 0.58 & & 0.00 & 0.20 & 0.21 \\
\hline Subscapular (mm) & $10.9 \pm 2.86$ & $11.3 \pm 2.70$ & $12.5 \pm 6.21$ & 1.30 & 0.28 & & 0.14 & 0.33 & 0.25 \\
\hline Suprailiac (mm) & $8.28 \pm 2.97$ & $8.90 \pm 2.99$ & $9.97 \pm 5.46$ & 1.64 & 0.20 & & 0.21 & 0.38 & 0.24 \\
\hline Abdomen (mm) & $11.4 \pm 4.51$ & $12.6 \pm 2.86$ & $12.4 \pm 6.34$ & 0.65 & 0.53 & & 0.32 & 0.18 & 0.04 \\
\hline Thigh (mm) & $10.7 \pm 3.84$ & $11.4 \pm 2.29$ & $11.7 \pm 4.40$ & 0.69 & 0.50 & & 0.22 & 0.24 & 0.09 \\
\hline Calf (mm) & $6.49 \pm 1.55$ & $7.72 \pm 1.17$ & $7.73 \pm 3.48$ & 3.71 & 0.03 & $1<2,3$ & $0.90 \S$ & 0.46 & 0.00 \\
\hline $\begin{array}{l}\text { Sum of seven } \\
\text { skinfolds (mm) }\end{array}$ & $63.4 \pm 17.1$ & $68.4 \pm 10.5$ & $72.1 \pm 33.1$ & 1.38 & 0.26 & & 0.35 & 0.33 & 0.15 \\
\hline \multicolumn{10}{|l|}{ Physiological tests } \\
\hline $10 \mathrm{~m}$ speed $(\mathrm{s}) \uparrow$ & $2.19 \pm 0.14$ & $2.24 \pm 0.16$ & $2.33 \pm 0.19$ & 6.09 & $<0.001$ & $1<3$ & 0.33 & $0.84 \S$ & 0.51 \\
\hline $20 \mathrm{~m}$ speed (s)ף & $3.50 \pm 0.22$ & $3.55 \pm 0.22$ & $3.63 \pm 0.24$ & 2.59 & 0.08 & & 0.23 & 0.56 & 0.35 \\
\hline $40 \mathrm{~m}$ speed (s)ף & $6.14 \pm 0.46$ & $6.20 \pm 0.60$ & $6.47 \pm 0.47$ & 4.39 & 0.02 & $1<3$ & 0.11 & $0.71 \S$ & 0.50 \\
\hline L-run test (s)ף & $6.49 \pm 0.34$ & $6.62 \pm 0.46$ & $6.67 \pm 0.27$ & 2.28 & 0.11 & & 0.32 & 0.59 & 0.13 \\
\hline $\begin{array}{l}\text { Vertical jump test } \\
(\mathrm{cm})^{\mathrm{wg}}\end{array}$ & $38.3 \pm 2.38$ & $34.9 \pm 2.82$ & $32.6 \pm 4.12$ & 29.9 & $<0.001$ & $\begin{array}{l}1>2,3 \\
2>3\end{array}$ & $1.30 \S$ & $1.69 \S$ & $0.65 \S$ \\
\hline Sit-and-Reach $(\mathrm{cm})^{\mathrm{wg}}$ & $6.12 \pm 5.10$ & $5.05 \pm 4.57$ & $8.56 \pm 2.01$ & 9.35 & $<0.001$ & $1,2<3$ & 0.22 & $0.63 \S$ & $0.99 \S$ \\
\hline $\begin{array}{l}2 \mathrm{~kg} \text { Medicine ball } \\
\text { chest throw }(\mathrm{m})^{\mathrm{wg}}\end{array}$ & $6.97 \pm 0.64$ & $5.91 \pm 0.86$ & $5.83 \pm 0.86$ & 26.2 & $<0.001$ & $1>2,3$ & $1.40 \S$ & $1.50 \S$ & 0.09 \\
\hline 60s Push Up (n) & $38.4 \pm 10.1$ & $35.6 \pm 8.90$ & $32.6 \pm 7.06$ & 3.61 & 0.03 & $1>3$ & 0.29 & $0.67 \S$ & 0.37 \\
\hline $\begin{array}{l}\text { Wall Sit Leg Strength } \\
(\mathrm{s})^{\mathrm{wg}}\end{array}$ & $132.1 \pm 6.61$ & $123.3 \pm 13.0$ & $121.2 \pm 23.0$ & 10.2 & $<0.001$ & $1,2>3$ & $0.85 \S$ & $0.64 \S$ & 0.11 \\
\hline $\begin{array}{l}\text { Yo-Yo Intermittent } \\
\text { Recovery Level } 1 \\
\text { (m) }{ }^{\text {wg }}\end{array}$ & $1307.3 \pm 228.6$ & $1030.7 \pm 269.6$ & $897.9 \pm 171.7$ & 36.6 & $<0.001$ & $\begin{array}{l}1>2,3 \\
2>3\end{array}$ & $1.11 \S$ & $2.03 \S$ & 0.59 \\
\hline
\end{tabular}

Game skills

\begin{tabular}{lcccccc}
$\begin{array}{l}\text { Tackling proficiency } \\
\text { test (\%) }\end{array}$ & $83.0 \pm 8.87$ & $68.3 \pm 7.94$ & - & $7.12^{\star \star}$ & $<0.001$ & $1.75 \S$ \\
\hline $\begin{array}{l}\text { Passing ability test } \\
\text { (au) }\end{array}$ & $105.9 \pm 4.86$ & $104.7 \pm 4.34$ & - & $1.12^{\star \star}$ & 0.27 & 0.26 \\
$\begin{array}{l}\text { Catching ability test } \\
\text { (au) }\end{array}$ & $71.7 \pm 2.06$ & $68.3 \pm 2.56$ & - & $6.19^{\star \star}$ & $<0.001$ & $1.46 \S$ \\
\hline
\end{tabular}

Playing experience=playing and training experience of competitive sport either rugby or cricket; catching ability=running and catching ability test; $\mathrm{F}=\mathrm{F}$ test for analysis of variance reporting the $\mathrm{p}$ value.

*Elite.

†Subelite.

‡Non-rugby.

§Moderate to large Cohen's d effect size (moderate effect: 0.6-1.2; large effect $>1.2$ ).

ПSample size was 26 for the subelite rugby players who performed these tests.

${ }^{\star *}$ The t-test results for between two groups comparisons.

wg, Welch F test reported and Games Howell test used for the post hoc analysis. 
no significant differences across playing standards. In terms of the rugby-specific game skills, elite rugby players showed better tackling proficiency $(\mathrm{t}=7.12, \mathrm{p}<0.001$, $\mathrm{ES}=1.75)$ and running and catching abilities $(\mathrm{t}=6.19$, $\mathrm{p}<0.001, \mathrm{ES}=1.46)$ than their subelite counterparts, with large practical differences between groups.

\section{DISCUSSION}

The main finding of this study was that VJ and Yo-Yo IRT L1 significantly improved with increasing competitive level. Another key finding was that elite U16 RU players showed significantly superior scores for rugby-specific game skills of tackling and catching than the sub-elite rugby players. This breadth of discriminant factors highlights the importance of physiological characteristics and rugby-specific game skills in competitive RU for elite U16 schoolboys. Specifically, these findings indicate that well-developed lower-body muscular power, prolonged high-intensity intermittent running ability/endurance, tackling proficiency and catching ability skills are possibly linked to the attainment of elite status in Zimbabwean U16 rugby players playing competitive schoolboy RU.

From the current study, it is unclear whether these findings indicate efficient specialist training of lowerbody muscular power, endurance, tackling and catching among U16 elite rugby players or preferential recruitment of powerful, physically enduring U16 players with better tackling and catching abilities in SESRL. It is also possible that both factors could account for the differences between groups. Given similar playing experience between groups, this probably negates the possible influence of playing history on test performances. However, specific details on the content or structure of the training routines for the elite, subelite and non-rugby players were not captured. Probably, this information is helpful in explaining the discriminant ability of VJ, Yo-Yo IRT L1, tackling and catching tests. Nevertheless, the current findings practically inform schoolboy coaches on the specific attributes required by schoolboy rugby players for the attainment of elite status in U16 competitive rugby through training in Zimbabwe.

There are limited studies specifically comparing anthropometric, physiological characteristics and rugby-specific game skills of U16 male adolescent RU players in the literature. Most studies offer a comparative analysis of adolescent rugby players from different age categories. ${ }^{37812}$ Although such studies provide data which has implications on identifying key characteristics in rugby, the main limitation of such studies is that between-group differences may reflect the possible influence of age, growth and biological maturation. Spamer $e t$ $a l^{11}$ compared characteristics of U16 rugby players from New Zealand (NZ, higher level) and South African (SA, lower level). Such age-specific comparisons are more likely to provide highly relevant information on the attributes important for rugby at the specified age category with little or no possible influence of age or maturity. Training differences, habituation or coaches' selection biases become fundamentally important in accounting for the observed test performances among same-aged players with different playing abilities. ${ }^{6}$ In the latter study, the elite NZ U16 players showed higher scores for VJ $(\mathrm{ES}=0.9)$ than elite SA U16, possibly reflecting superior explosive power capabilities in higher-level athletes.

Given no differences in sum of skinfolds observed across playing standards, the fact that elite U16 RU players had greater body mass than cricketers $(E S=0.90)$ suggest increased lean mass for the elite RU players. Reportedly, increased muscle mass is an important determinant of muscle strength. ${ }^{17}$ This probably explains better upper and lower muscular strength values for the elite U16 compared with other groups. Moderate practical significant differences (ES=0.67) were observed for the $60 \mathrm{~s}$ Push Up test and Wall Sit Leg Strength test $(\mathrm{ES}=0.64)$ between elite and cricket players. Since greater levels of muscular strength are likely to produce better power output, ${ }^{17}$ this probably explains the high upper-andlower body muscular power performances of elite U16 rugby players compared with other groups. The implications of these results are that schoolboy rugby coaches may aim to devise training methods facilitating development of muscular strength and power to enhance playing potential of non-rugby or subelite players during talent identification and recruitment.

Jones $e t$ at compared the physical qualities of academy (higher level) and school-level (lower level) U18 RU players observing small practical differences between groups for the Yo-Yo IRT L1. However, in the current study, elite U16 rugby players had better Yo-Yo IRT L1 test scores than subelite rugby players (ES=1.11) and non-rugby players $(\mathrm{ES}=2.03)$. Population and age-related differences could explain results discrepancy between Jones et $a t^{6}$ and the current study (U18 RU English vs U16 RU Zimbabwe). Given these differences, it is also possible that endurance qualities may have a greater impact in determining higher playing standards in U16 RU than in U18 RU.

In a related sport of rugby league (RL), Johnston et $a l^{18}$ found that the high-standard junior players $(16.6 \pm 0.5$ years) covered greater distances compared with the low-standard players $(16.5 \pm 0.6$ years $)$ on the Yo-Yo IRT L1 $(1420 \pm 337 \mathrm{~m}$ vs $922 \pm 227 \mathrm{~m})$. Although these findings relate to a different sport, they add support to the possibility of endurance qualities having greater discriminative ability in younger adolescents playing competitive intermittent team sports. The latter authors attributed the differences to increased physical demands associated with higher standards of competition necessitating optimal physical fitness levels in participating players. In the current study, the fact that subelite rugby players also showed high scores for the Yo-Yo IRT L1 relative to the non-rugby players is an indication that endurance is an important fitness component in the sport of rugby than in cricket. From a practical perspective, schoolboy coaches should continuously emphasise the development of endurance in potential adolescent rugby players identified or selected for U16 rugby competitions. 
In the present study, $10 \mathrm{~m}, 20 \mathrm{~m}$ and $40 \mathrm{~m}$ speed tests failed to discriminate elite U16 rugby players from their subelite counterparts. Although in RL, Till et $a l^{19}$ also showed no significant differences in the $10 \mathrm{~m}$ and $20 \mathrm{~m}$ sprints among U15 players playing amateur $(15.6 \pm 0.25$ years), academy ( $15.6 \pm 0.29$ years) and professional rugby (15.5 \pm 0.30 years). Jones $e t a t^{6}$ reported consistent results for $10 \mathrm{~m}, 20 \mathrm{~m}$ and $40 \mathrm{~m}$ speed tests between academy and school-level U18 RU players. Lack of speed differences between rugby players probably dismisses sprinting abilities as important determinants of higher playing standards in Zimbabwe schoolboy rugby or shows its equal importance in both competitive leagues and the need for continued training. Evidence from a recent systematic review showed that speed is the most commonly investigated physiological characteristic among rugby players especially $10 \mathrm{~m}, 20 \mathrm{~m}$ and $40 \mathrm{~m}$ sprint time. ${ }^{20}$ Similarities in chronological age, playing experience, body mass, height and skinfolds between the elite and the subelite players probably explain the similar sprinting time.

Another important finding of this study was that elite U16 rugby players had better scores for tackling and catching compared with subelite rugby players. Cognisant of the cross-sectional design of the study, these findings suggest that tackling proficiency and catching ability skills could be used in the Zimbabwean context to discriminate U16 RU playing at different levels of competition. Practically, this hints to the coaches the importance of skill training incorporating tackling and catching skills among U16 RU players. A recent review showed that tackling and catching represent important technical elements in rugby and are commonly evaluated among rugby players. ${ }^{21}$ However, there are limited studies comparing game-specific skills of elite U16 to subelite U16 RU players in the literature. Studies from related intermittent contact team sports such as RL which also emphasise tackling and catching have reported consistent results. For example, Gabbett $e t a l^{22}$ showed that first-grade RL players $(23.7 \pm 4.3$ years $)$ had greater catching ability scores compared with secondgrade players (24.4 \pm 5.0 years). In another study, Gabbett $e t a l^{23}$ showed differences in tackling proficiency between the lesser-skilled (22.3 \pm 3.5 years) and the higher-skilled

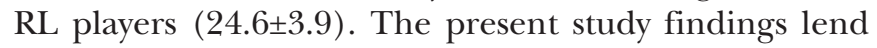
support to the possible discriminative ability of tackling and catching although at U16 competitive level in schoolboy RU. Given the similar ages and playing experiences between elite and subelite players, other factors such as differences in upper and lower body muscular power and specific training approaches for technical skills may also account for the discriminative ability of these tests in the current study. The significantly higher VJ and $2 \mathrm{~kg}$ Medicine Ball Chest Throw (2 kg MBCT) scores for elite U16 RU players would certainly advantage the arm-wrapping capabilities of the tackler and leg drive performances during tackle execution. ${ }^{24}$

An unexpected finding for the present study was the small effect size differences between the elite and subelite
U16 for the passing ability skill test. This was despite the elite players showing better tackling and catching skills. Given the importance of passing in rugby as evidenced by the number of studies investigating the passing ability of RU or RL players, ${ }^{21}$ these findings probably indicate similar proficiency in passing abilities between elite and subelite U16 RU playing competitive rugby in Zimbabwean schools. Consistently, passing components failed to show discriminative ability between NZ U16 players and SA U16 rugby players. ${ }^{11}$ This was largely because the two groups were a representation of elite players in their respective countries. Also, Gabbett $e t$ a $t^{22}$ shared similar findings of no statistically significant difference in basic passing skills between first-grade ( $23.7 \pm 4.3$ years) and second-grade (24.4 \pm 5.0 years) RL players. However, there were significant differences between first $(23.7 \pm 4.3$ years) and third grade (17.8 \pm 1.5 years) players possibly reflecting the influence of different ages, playing and training experience (online supplementary file 1$)^{25-46}$.

This study had some limitations that need consideration when interpreting obtained results. Due to lack of technical competency and local cricket coaches' reservations, U16 cricket players were not assessed for game-specific skills. This indirectly points out to the importance of these technical abilities to the sport of rugby. A further limitation of the present study was cross-sectional examination of players representing one age-category conveniently derived from selected schools. This limits generalisability of the study findings to other age groups and to rest of the schoolboy rugby players playing U16 RU in Zimbabwe. Future studies in this area of research may aim to compare playing at different age categories (U16 vs U19) or include a large random sample of U16 from various school teams playing in the SESRL and CESRL. The sample size was small to allow for player position categorisation. Participant testing was conducted during the rugby and cricket competitive season during training hours. The possible influence of residual fatigue may have influenced the cross-sectional test performances. However, an attempt was made to intersperse with 48 hours the performance of the most physically demanding tests. The SCRuM test battery only had anthropometric, physiological and coach-rated rugby skills in its multidimensional attempt; however, a more holistic test battery encompassing all the elements important in rugby such as technical, tactical and psychological measures would have been appropriate. The selection of cricket players as a control group was arbitrary decision premised on reported differences in physical, physiological and technical demands with rugby. However, it is possible that there could be certain competencies that could be similar between the sports influencing the observed results.

\section{CONCLUSION}

The present study set to identify anthropometric, physiological and rugby-specific skills discriminating U16 RU players by level of competition. Although elite U16 RU 
players demonstrated superior scores for most physiological characteristics and game-specific skills compared with subelite and non-rugby players, only the test scores for VJ, Yo-Yo IRT L1, tackling and catching ability skills tests significantly improved with increasing competitive level. Such findings implies that lower-body muscular power, prolonged high intensity intermittent running ability, tackling and catching effectively discriminates elite rugby players from subelite and non-rugby players and also differentiates subelites from the non-rugby players. From a practical perspective, schoolboy rugby coaches need to facilitate the development and maintenance through continuous training of such qualities and skills among U16 schoolboy rugby players.

Acknowledgements The authors would like to acknowledge all the high school male adolescent rugby and cricket players who participate in this study. Further, we would like extend our gratitude to the parents and guardians who gave informed consents for their child to participate in the study. The lead author would like to thank all the research assistants who collected part or whole data on this project including Mr Sander Oorschot, Mr Takura Matare, Miss Sharmaine Chizanga, Mr Intelligent Ndlovu, Mr Malan Chitevuka and Mr Mike Chiwaridzo.

Contributors MC, BCMS-E and GDF originally developed the concept and design of the study. MC is a doctoral student at UCT and this manuscript is part of his doctoral thesis. $\mathrm{MC}$ acted as the lead investigator under the guidance, mentorship and supervision of BCMS-E and GDF. MC conducted the literature review, recruited and trained research assistants and participants with variable assistance coming from other people who were acknowledged in the acknowledgment section. MC supervised the data collection. MC drafted the manuscript for publication and acted as the corresponding author. BCMS-E and GDF performed critical revision of the manuscript, statistical input, and provided extensive revisions prior to submission to the journal for review. All the authors read and approved the final version of the manuscript.

Funding The authors have not declared a specific grant for this research from any funding agency in the public, commercial or not-for-profit sectors.

Competing interests None declared.

Patient consent for publication Not required.

Ethics approval The study was approved by University of Cape Town Human Research Ethical Committee (HREC ref: 016/2016). Ethical approval was further granted by the Medical Research Council of Zimbabwe (MRCZ ref: A/2070) since the study involved Zimbabwean participants.

Provenance and peer review Not commissioned; externally peer reviewed.

Data availability statement Data are available upon reasonable request.

Open access This is an open access article distributed in accordance with the Creative Commons Attribution Non Commercial (CC BY-NC 4.0) license, which permits others to distribute, remix, adapt, build upon this work non-commercially, and license their derivative works on different terms, provided the original work is properly cited, appropriate credit is given, any changes made indicated, and the use is non-commercial. See: http://creativecommons.org/licenses/by-nc/4.0/.

\section{REFERENCES}

1. Viviers PL, Viljoen JT, Derman W. A review of a decade of rugby Union injury epidemiology: 2007-2017. Sports Health 2018;10:223-7.

2. Thomas GL, Wilson MR. Introducing children to rugby: elite coaches' perspectives on positive player development. Qual Res Sport Exerc Health 2014;6:348-65.

3. Krause LM, Naughton GA, Denny G, et al. Understanding mismatches in body size, speed and power among adolescent rugby union players. J Sci Med Sport 2015;18:358-63.

4. Hartwig TB, Naughton G, Searl J. Motion analyses of adolescent rugby union players: a comparison of training and game demands. $J$ Strength Cond Res 2011;25:966-72.

5. Tee JC, Coopoo Y. Movement and impact characteristics of South African professional rugby union players. S Afr J SM 2015;27:33-9.
6. Jones B, Weaving D, Tee J, et al. Bigger, stronger, faster, fitter: the differences in physical qualities of school and Academy rugby union players. J Sports Sci 2018;36:2399-404.

7. Kobal R, Nakamura FY, Moraes JE, et al. Physical performance of Brazilian rugby players from different age categories and competitive levels. J Strength Cond Res 2016;30:2433-9.

8. Darrall-Jones JD, Jones B, Till K. Anthropometric and physical profiles of English Academy rugby union players. J Strength Cond Res 2015;29:2086-96.

9. Lombard WP, Durandt JJ, Masimla H, et al. Changes in body size and physical characteristics of South African under-20 rugby union players over a 13-year period. J Strength Cond Res 2015;29:980-8.

10. Smart DJ, Gill ND. Effects of an off-season conditioning program on the physical characteristics of adolescent rugby union players. J Strength Cond Res 2013;27:708-17.

11. Spamer EJ, du Plessis D, Kruger EH. Comparative characteristics of elite New Zealand and South African $\mathrm{u} / 16$ rugby players with reference to gamespecific skills, physical abilities and anthropometric data. S. Afr. j. sports med. 2009;21:53-7.

12. Durandt J, Du Toit S, Borresen J, et al. Fitness and body composition profiling of elite junior South African rugby players. $S$ Afr J Sports Med 2006;18:38-45.

13. Van Gent MM, Spamer EJ. Comparisons of positional groups in terms of anthropometric, rugby-specific skills, physical and motor components among $\mathrm{U} 13, \mathrm{U} 16, \mathrm{U} 18$ and $\mathrm{U} 19$ elite rugby players. Kinesiology 2005;37:50-63.

14. Rugby W. Junior rugby laying foundations in Zimbabwe, 2019. Available: https://www.world.rugby/news/26021?lang=en. Last[Accessed 2 May 2019].

15. Chiwaridzo M, Chandahwa D, Oorschot S, et al. Logical validation and evaluation of practical feasibility for the SCRuM (school clinical rugby measure) test battery developed for young adolescent rugby players in a resource-constrained environment. PLoS One 2018;13:e0207307.

16. Martin V, Sanchez-Sanchez J, Ramírez-Campillo R, et al. Validity of the RSA-RANDOM test for young soccer players. Int J Sports Med 2018;39:813-21.

17. Argus CK, Gill ND, Keogh JWL. Characterization of the differences in strength and power between different levels of competition in rugby Union athletes. J Strength Cond Res 2012;26:2698-704.

18. Johnston RD, Gabbett TJ, Jenkins DG. Influence of playing standard and physical fitness on activity profiles and post-match fatigue during intensified junior rugby League competition. Sports Med Open 2015;1.

19. Till K, Cobley S, Morley D, et al. The influence of age, playing position, anthropometry and fitness on career attainment outcomes in rugby League. J Sports Sci 2016;34:1240-5.

20. Chiwaridzo M, Oorschot S, Dambi JM, et al. A systematic review investigating measurement properties of physiological tests in rugby. BMC Sports Sci Med Rehabil 2017;9:24.

21. Oorschot S, Chiwaridzo M, CM Smits-Engelsman B. Psychometric evaluation of commonly used game-specific skills tests in rugby: a systematic review. BMJ Open Sport Exerc Med 2017;3.

22. Gabbett T, Kelly J, Pezet T. Relationship between physical fitness and playing ability in rugby League players. $J$ Strength Cond Res2007;21:1126-33.

23. Gabbett TJ, Jenkins DG, Abernethy B. Relative importance of physiological, anthropometric, and skill qualities to team selection in professional rugby League. J Sports Sci 2011;29:1453-61.

24. Baker DG, Newton RU. Comparison of lower body strength, power, acceleration, speed, agility, and sprint momentum to describe and compare playing RANK among professional rugby League players. $J$ Strength Cond Res 2008;22:153-8.

25. Norton K, Marfell-Jones M, Whittingham N, et al. Anthropometric assessment protocols. In: Gore CG, ed. Physiological tests for elite athletes. Champaign, IL: Human Kinetics, 2000: 66-85.

26. Mirwald RL, Baxter-Jones ADG, Bailey DA, et al. An assessment of maturity from anthropometric measurements. Med Sci Sports Exerc 2002;34:689-94.

27. Darrall-Jones JD, Jones B, Roe G, et al. Reliability and usefulness of linear sprint testing in adolescent rugby Union and League players. $J$ Strength Cond Res 2016;30:1359-64.

28. Wang R, Hoffman JR, Tanigawa S, et al. Isometric mid-thigh pull correlates with strength, sprint, and agility performance in collegiate rugby union players. J Strength Cond Res 2016;30:3051-6

29. La Monica MB, Fukuda DH, Miramonti AA, et al. Physical differences between forwards and backs in American collegiate rugby players. $J$ Strength Cond Res 2016;30:2382-91.

30. Hetzler RK, Stickley CD, Lundquist KM, et al. Reliability and accuracy of handheld stopwatches compared with electronic 
timing in measuring sprint performance. $J$ Strength Cond Res 2008;22:1969-76.

31. Mayhew JL, Houser JJ, Briney BB, et al. Comparison between hand and electronic timing of 40-yd DASH performance in college football players. J Strength Cond Res 2010;24:447-51.

32. Gabbett TJ. Physiological and anthropometric characteristics of amateur rugby League players. Br J Sports Med 2000;34:303-7.

33. Keogh J. The use of physical fitness scores and anthropometric data to predict selection in an elite under 18 Australian rules football team. J Sci Med Sport 1999;2:125-33.

34. Gabbett TJ, Kelly JN, Sheppard JM. Speed, change of direction speed, and reactive agility of rugby league players. $J$ Strength Cond Res 2008;22:174-81.

35. Till K, Cobley S, O'Hara J, et al. A longitudinal evaluation of anthropometric and fitness characteristics in junior rugby league players considering playing position and selection level. J Sci Med Sport 2013;16:438-43.

36. Hendricks S, Lambert M, Masimla $\mathrm{H}$, et al. Measuring skill in rugby Union and rugby League as part of the standard team testing battery. Int J Sports Sci Coach 2015;10:949-65.

37. Gabbett TJ, Jenkins DG, Abernethy B. Relationships between physiological, anthropometric, and skill qualities and playing performance in professional rugby League players. J Sports Sci 2011;29:1655-64.

38. Gabbett T, Ryan P, technique T. Tackling technique, injury risk, and playing performance in high-performance collision sport athletes. Int J Sports Sci Coach 2009;4:521-33.
39. Gabbett TJ. Physiological and anthropometric correlates of tackling ability in rugby League players. J Strength Cond Res 2009;23:540-8.

40. Waldron M, Worsfold P, Twist C, et al. The reliability of tests for sport-specific skill amongst elite youth rugby League players. Eur J Sport Sci 2014:14:sup1:S471-S477.

41. Speranza MJA, Gabbett TJ, Johnston RD, et al. Relationship between a standardized tackling proficiency test and Match-Play tackle performance in Semiprofessional rugby League players. Int $J$ Sports Physiol Perform 2015;10:754-60.

42. Pienaar AE, Spamer MJ, Steyn HS. Identifying and developing rugby talent among 10-year-old boys: a practical model. J Sports Sci 1998;16:691-9.

43. Stuart GR, Hopkins WG, Cook C, et al. Multiple effects of caffeine on simulated high-intensity team-sport performance. Med Sci Sports Exerc 2005;37:1998-2005.

44. Spamer EJ, Anthropometric DlaP. Physical, motor, and gamespecific profiles of elite U-16 and U-18 year-old South African schoolboy rugby players. Kinesiology 2006;38:176-84.

45. Gabbett TJ. Physiological and anthropometric characteristics of starters and non-starters in junior rugby League players, aged 13-17 years. J Sports Med Phys Fitness 2009;49:233-9.

46. Gabbett TJ, Jenkins DG, Abernethy B. Physiological and anthropometric correlates of tackling ability in junior elite and subelite rugby League players. J Strength Cond Res 2010;24:2989-95. 